\title{
Espaço para o recomeço, com Eros
}

\section{Ana Pais}

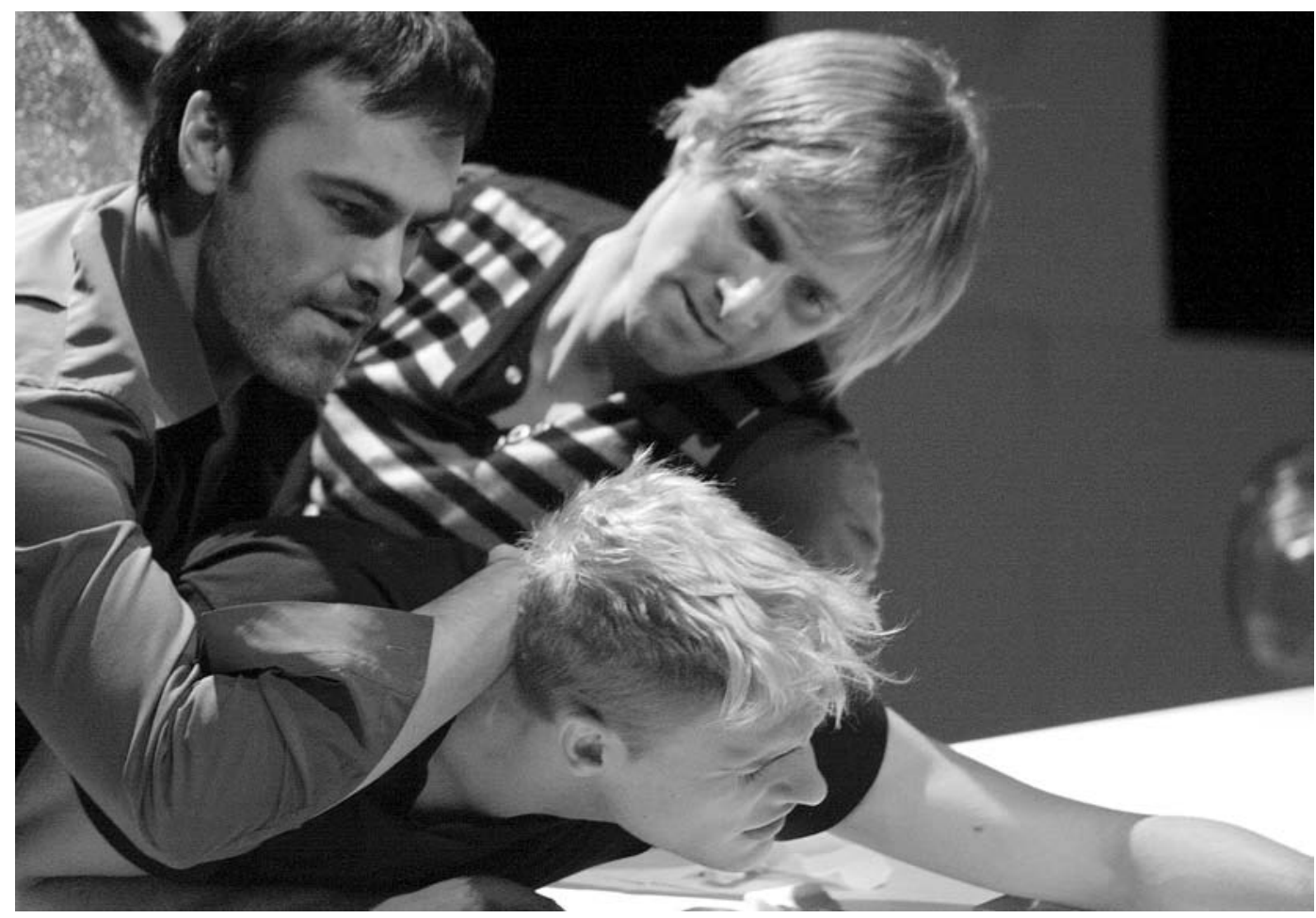

Em 2001, Aleks Sierz baptizou a emergente e explosiva dramaturgia britânica com a expressão in-yer-face theatre (qualquer coisa como "teatro de choque", em português). Sublinhando um carácter agressivo e provocatório, este termo procura descrever um estilo contemporâneo de composição escrita e cénica típico dos anos 90 em Inglaterra, em que o espectador está literalmente na mira de um disparo. Este teatro estoira-Ihe na cara, confrontao com imagens, sensações e realidades que não poderá, dai em diante, ignorar pois elas invadem-no, chocam-no, tomam conta do seu espaço íntimo, numa palavra, exploram os limites emocionais e sociais entre o palco e a plateia. Não será, portanto, difícil saber quando estamos perante um espectáculo deste género. Segundo o crítico, não é mesmo nada difícil: "a linguagem é obscena, há nudez em cena, as pessoas fazem sexo à nossa frente, há violência a rodos, uma personagem humilha outra, quebram-se tabus, toca-se publicamente em assuntos indiziveis, subvertem-se as estruturas dramáticas convencionais"1. De facto, dificil seria não o reconhecer. Passados quase vinte anos desde o surgimento desta nova sensibilidade, que pouco deve à subtileza, mas que é profundamente marcada por uma crítica visceral da sociedade, o grito demolidor de angústia e asco do teatro que tenha verdadeiramente mudado a paisagem do sofrimento nem se tenham alterado os esquemas sistemáticos que o geram, mas porque nos habituámos a ele. À força das inúmeras encenações, traduções, dissecações do teatro in-yer-face, habituámo-nos a ignorar a sua dor, a sua raiva. Consumimos o seu efeito de choque. Assim também, habituámo-nos a pensar e a ver representados os autores do teatro in-yer-face sob um determinado prisma: o da tragédia, da escuridão, da escatologia, da agressividade. Talvez por isso, pudessemos mesmo pensar em textos como Foder e ir às compras, de in-yer-face é hoje escutado com outra serenidade. Não
Foder e ir às compras, de Mark Ravenhill, enc. Gonçalo Amorim, Primeiros Sintomas / CCB, 2007 (Pedro Carmo, Romeu Costa e Carloto Cotta), fot. Maria José Silva.

Aleks Sierz, http://wwwinyerfacetheatre.com, 06.03.2008 Ana Pais é professora da Escola Superior de Teatro e Cinema e crítica do semanário Sol. 


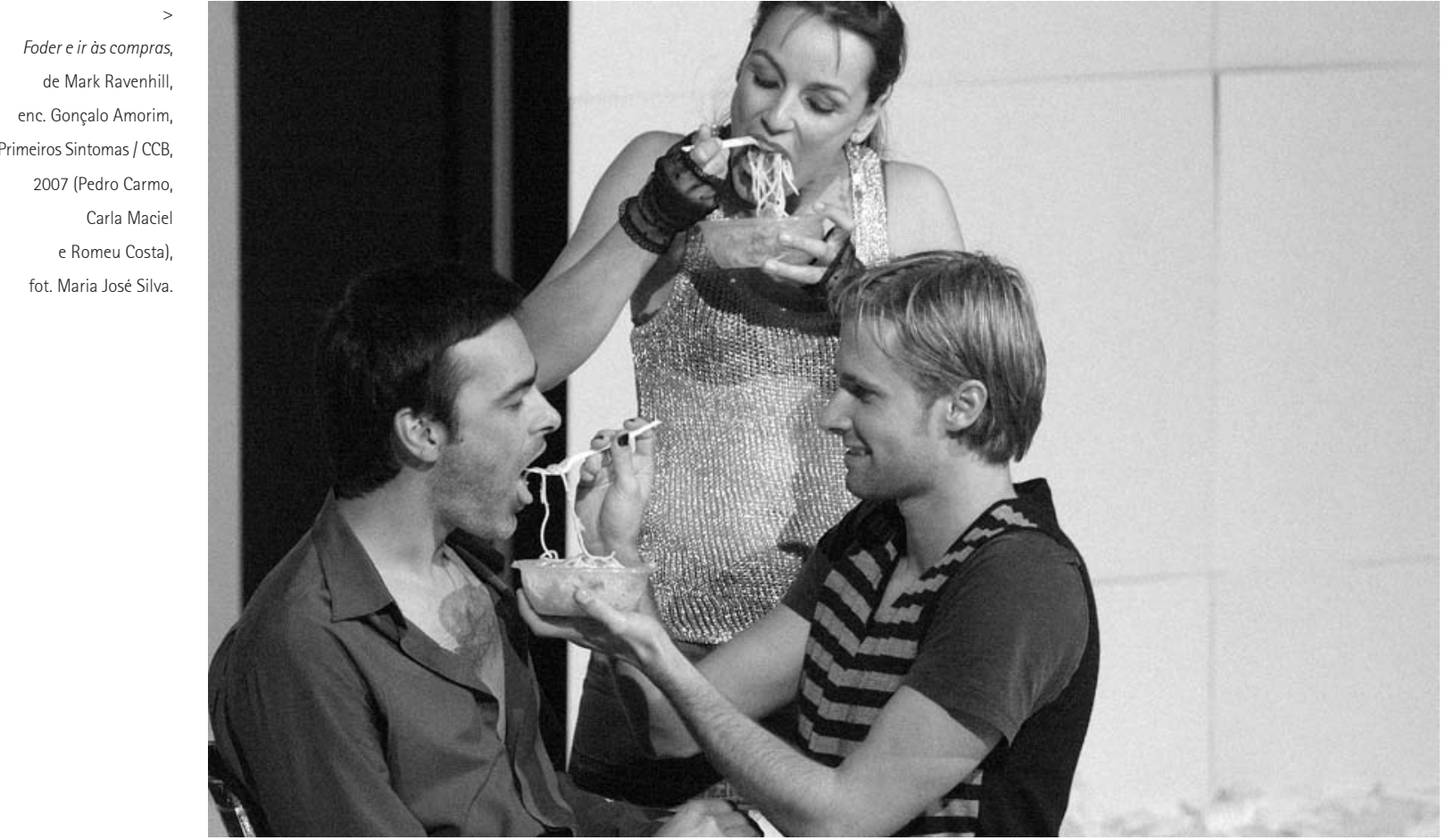

Mark Ravenhill - uma das referências autorais deste estilo - como textos "datados", pertencentes a uma estética em vias de esgotamento.

E eis que se instala a dúvida: como pode hoje este teatro causar o mesmo efeito de anteriormente face a um espectador exposto, habituado a (e preparado para) tais experiências? Por que razão levar à cena um texto cuja função central não poderá ser cumprida? 0 espectáculo Foder e ir às compras, co-produzido pela companhia Primeiros Sintomas e o Centro Cultural de Belém, numa encenação de Gonçalo Amorim, oferece-nos motivos de peso, que levaram o júri nomeado pela APCT a destacálo com o Prémio da Crítica 2007 (ex aequo com A tragédia de Júlio César, pela Cornucópia).

Uma década depois da sua estreia, em 1996 no Royal Court Theatre em Londres, um conjunto pontual de fazedores de teatro leva à cena Shopping and Fucking (Foder e ir ás compras) em Lisboa, no ano de 2007. Não sendo a estreia nacional desta obra (foi antes produzida pelo Teatro Plástico em 1999 e posteriormente encenada por Carlos Afonso Pereira em 2006), esta produção evidencia-se pelo modo como se apropria de uma linguagem dramática e de uma sensibilidade cénica, muito marcada por uma inquietude finessecular, e a desloca milimetricamente de um imaginário fétiche para um território ambiguamente decadente e confortável. Através de um olhar refrescante sobre o texto, o trágico quadro de Foder e ir às compras surge-nos com uma punjança arrebatadora, a um tempo turbulenta e magnetizante. As situações dramáticas sustentam-se sempre num ambiente de tensão entre uma coloquialidade realista, no caso, extremamente bem cuidada e fluída na tradução de Ana Bigotte Vieira, e um desnudamento de corpos, intensidades e emoções, rasgando as fronteiras entre o que é admissive ver na cena e aquilo que pertence à esfera da vida privada. Obviamente, no seu tumulto, este rasgão obsceno pode ferir susceptibilidades. Mas não é exactamente por isso que o espectáculo magnetiza. Isso seria fácil, dados os ingredientes da "fórmula" in-yer-face. É que toda a tensão, ambientada num espaço sem identidade, sem elementos pessoais e, por isso, quase abstracto e até minimalista, que Rita Abreu construiu como que numa evocação dos grandes hipermercados - como é típico dos não-lugares da contemporaneidade diagnosticados por Marc Augé -, corroborada pelos adereços e figurinos de Ana Limpinho e Maria João Castelo, é, sobretudo, gerida pelo deslumbrante elenco e lançada como uma força pulsional para o público, enredando-o. Ambivalente na forma como manipula um jogo de atracção e repulsa entre os actores e entre o palco e a plateia, o espectáculo assenta numa leitura dramatúrgica surpreendente e bem fundamentada, tanto ganhando contornos sombrios quanto apelando a uma ironia empática.

Encenar este texto de Ravenhill significa regressar ao grande tema do sofrimento humano, exposto em ferida aberta no contexto da sociedade ocidental, consumista, hedonista e lacunar em valores e estruturas institucionais. Vagueando como átomos perdidos na órbita aniquiladora das dependências, as três personagens centrais - Mark, Robbie e Lulu - estão reunidas nesta proposta através de uma espécie de núcleo familiar em colapso que tem, na sua base, não afectos mas uma "transacção": Mark compra a outro homem o casal Robbie e Lulu num supermercado, ou assim nos é apresentado o momento em que se conheceram. 0 texto inverte o mito original - a narrativa fundadora - da família apresentando-o como uma transação: por um lado, configurando um casal, Robbie e Lulu precisam, paradoxalmente, de alguém que tome conta deles, tal como o adolescente Gary, que a "família" sacrifica para sua salvação financeira com uma espécie de ritual iniciático, começado justamente com a evocação dessa mesma história, a favorita de Robbie e Lulu. Por outro lado, Mark, que podia ser o filho, representa uma figura parental que os abandona, em virtude de uma estadia numa clínica de reabilitação. Mark é dependente não só de drogas pesadas, como também de afecto - 0 sexo para ele é possivel apenas enquanto transacção -, 


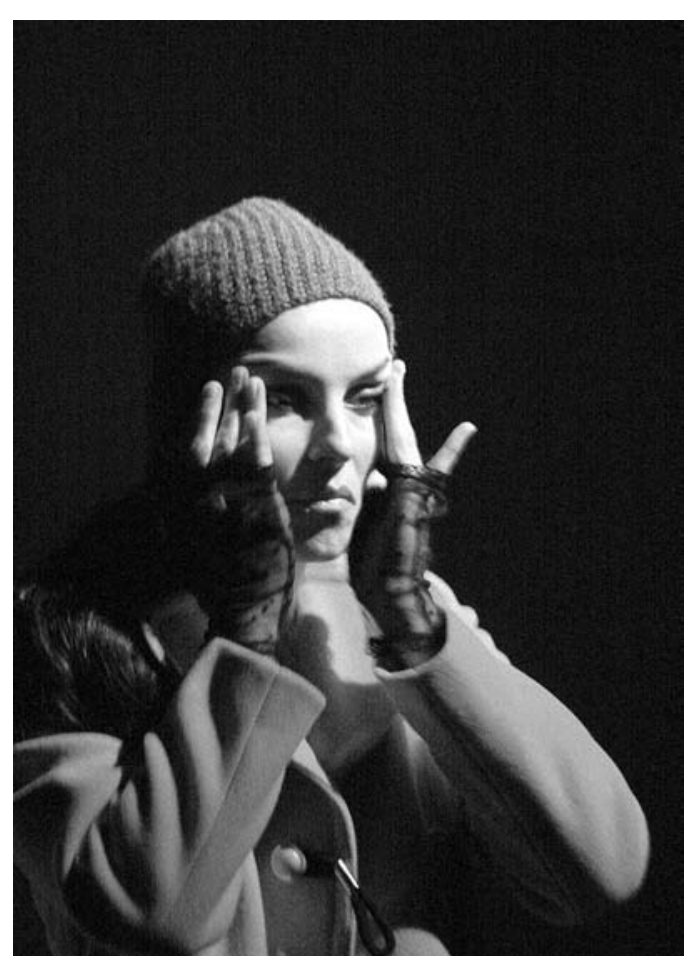

pelo que a espiral de desencontros, fragilidades e buracos negros se expande indefinidamente. Nesta voragem, 0 dinheiro compra droga, sexo e produtos vários em lojas e supermercados, mas nada substitui o que manifestamente falta a todas as personagens - amor, segurança e autonomia, os pilares básicos de um crescimento saudável.

Embora o texto dê indicações claras de que as relações entre as personagens se assemelham às de uma familia tradicional, denunciando, consequentemente, a sua ruína enquanto ancoradouro de valores e confiança, nada obriga a vermos em palco a sua dinâmica afectiva. Aliás, seria mais óbvio e útil para um tratamento de choque do espectador sublinhar a violência e revolta através dessa dinâmica. E é essa evidência que esta proposta não reitera. Desdobrando lentamente a relação entre as personagens numa ambiguidade entre a frustração e o desamor, por um lado, e a cumplicidade e a ironia, por outro, a opção da encenação foi a de criar um outro plano de entendimento deste universo sombrio. Ao evitar o tom provocatório do teatro in-yer-face, que em tudo depende das interpretações, Gonçalo Amorim evitou igualmente o cliché da sua representação, muitas vezes confundido com a violência gratuita. 0 encenador encontrou na dramaturgia da ambivalência uma delicadeza, uma frescura e um conforto surpreendentes para uma paisagem absolutamente inóspita, demonstrando uma cativante inteligência no modo como articula as matérias da cena no espectáculo: actores, texto, cenário, música e movimento, tudo conflui para uma poderosa e vibrante respiração, fazendo o espectáculo pulsar a um só ritmo.

Inevitavelmente, este ritmo sustenta-se no pilar inabalável do elenco. Carla Maciel, Carloto Cotta, Pedro Carmo, Pedro Gil e Romeu Costa são os actores que se entregam, diríamos, literalmente de corpo e alma na construção de uma partitura de gestos, tonalidades e temperaturas: do desalento mais soturno - e da petrificante violência de um ritual - ao riso cristalino e até mesmo à ternura contagiante de um regresso a casa, depois de passada a tempestade. A harmonia, a intensidade e a generosidade das suas interpretações superam qualitativamente qualquer expectativa no que toca ao domínio do corpo, da palavra, da voz e da capacidade de escuta dos movimentos de conjunto. Irrepreensíveis, os actores dão mostras de uma sintonia e de um rigor reveladores de um trabalho colectivo e empenho tão assinaláveis (e, é preciso dizê-lo, a duríssimas penas financeiras e logísticas) quanto imprescindiveis para atingir resultados como este. Na sua fluidez macia, o espectáculo é atravessado ainda por um forte erotismo, determinado não só pela linguagem e pelas acções dramáticas do texto mas também, e muito particularmente, pela carga sensual com que o elenco, elegantemente, contamina toda a cena. E é esta última, que reside na voluptuosidade tanto da carne quanto dos afectos, a responsável primeira por desviar o espectáculo do registo provocatório mais evidente. Clarividente face ao perigo da saturação de um estilo, o pequeno desvio amplia-se num passo notável: o elenco transforma um texto in-yer-facenum espectáculo in-yerheart - directo ao coração. Como uma flecha de cupido, o espectáculo acerta em cheio no alvo do sentimento, aproveitando o rasgo aberto no íntimo do espectador para dosear violência e ternura. Deste modo, ele actualiza o choque inerente à obra num erotismo que tanto atrai quanto provoca repulsa, tanto nos aproxima com pequenas ironias, gestos de cumplicidade e doçura (de que é emblemática a última cena), quanto perturba e nos afasta com a violência da carne e das situações.

É evidente que a obscenidade, o sexo, a violência, a humilhação, os tabus in-yer-face continuam lá, mas como que numa expressão suavizada do trágico, pelo riso e pelo amor; como se o trágico tivesse sido superado, como se, por algum estranho motivo, conseguissemos sobrevoar a paisagem negra; como se o próprio espectáculo nos libertasse dos fantasmas freudianos e dos mil espectros da pós-modernidade exaurida, abrindo, vagarosamente, espaço para o recomeço, com Eros.
Foder e ir às compras, de Mark Ravenhill, enc. Gonçalo Amorim, Primeiros Sintomas / CCB, 2007 (Carla Maciel), fot. Maria José Silva. 